\title{
From Experimental Interaction to the Brain as the Epistemic Object of Neurobiology
}

\author{
Gesa Lindemann
}

Published online: 11 June 2009

(C) Springer Science+Business Media B.V. 2009

\begin{abstract}
This article argues that understanding everyday practices in neurobiological labs requires us to take into account a variety of different action positions: self-conscious social actors, technical artifacts, conscious organisms, and organisms being merely alive. In order to understand the interactions among such diverse entities, highly differentiated conceptual tools are required. Drawing on the theory of the German philosopher and sociologist Helmuth Plessner, the paper analyzes experimenters as self-conscious social persons who recognize monkeys as conscious organisms. Integrating Plessner's ideas into the stock of concepts used in science and technology studies provides richer descriptions of laboratory life. In particular, this theory allows an understanding of a crucial feature of neurobiological brain research: the construction of the brain as the epistemic object of brain research. As such, the brain must be isolated from the acting and interacting organism in a complicated process.
\end{abstract}

Keywords Actor - Brain - Epistemological object - Human-monkey interaction · Plessner $\cdot$ Representation $\cdot$ Second person perspective $\cdot$ Science studies

At a conference three neuroscientists discuss the problem of whether monkeys are able to count or not. First scientist: A monkey cannot count. That's impossible. They do not have a concept of number. The second scientist replies: Well, maybe they can count up to 2 or 3 , but that's it. The third

This article presents results from the research project "Consciousness and anthropological difference" funded by the German Research Council. I am indebted to H. Kalthoff, C. Hauskeller and two anonymous reviewers of Human Studies for their helpful comments on earlier drafts of the paper.

G. Lindemann ( ()

Institute for Social Sciences, Carl-von-Ossietzky-University, Ammerländer Heerstr. 114-118,

26129 Oldenburg, Germany

e-mail: gesa.lindemann@uni-oldenburg.de 
scientist rejects both opinions: Of course monkeys can count. They always stop working before the last block of trials and ruin your whole experiment. (Fieldnotes)

This joke was told to me by a neurobiologist after an experimental session in which the monkey subject did not perform as many trials as the scientist needed. It describes the complicated and emotionally charged relationship between experimenters and their monkeys. Nonhuman primates are demanding experimental subjects. ${ }^{1}$ They contribute in many ways to the success (or failure) of an experiment. In order to understand their contribution, we must take into account a variety of different action positions. There are self-conscious social actors and technical artifacts, there are organisms which relate consciously to their environment, and there are organisms which are merely alive but not conscious.

To understand the interactions among such diverse entities, highly differentiated conceptual tools are required. It is not only the difference between the technical and the social which is at issue: social persons interact not only with technical artifacts but also with organisms. Sometimes these interactions are mediated by technical artifacts, but sometimes they are direct interactions between the experimenter and the organism itself. In analyzing such settings, we are confronted with the following questions: What are the differences between the social and the organic, or between the organic and the technical? How do conscious organisms relate to social actors? Or: How do conscious organisms relate to technological artifacts?

In order to make sense of such differences, I draw on Helmuth Plessner's (1928) theory of positionality. In terms of methodology his work is based on a broad concept of understanding. Understanding is a methodology appropriate to a second-person perspective. This methodology is usually restricted to an analysis of interactions among symbol-using beings_-like humans_-but Plessner goes further by applying a second-person perspective also to the analysis of the interactions with beings and among beings who do not use symbols. Integrating his ideas into the stock of concepts used in STS provides richer descriptions of laboratory life. It enables us to show that in order to perform their experiments, neuroscientists have to understand their research subjects, but do not need to treat them as self-conscious social actors.

Using the theory of positionality, the relevance of the living organism as an important actor in the experimental setting becomes obvious. In particular, it allows an understanding of a crucial feature of neurobiological brain research: the epistemic object of such research is the isolated brain as a system. During the experiment's initial phases, the interaction between the experimenter and the organism is crucial, but in the phase of preparing and analyzing data it is the brain which becomes the system of interest. The final step of data analysis nonetheless depends on a particular structure of the interaction between an experimenter and his/ her subject. Completion of the experiment requires that the conscious organism does not exist as a social person.

\footnotetext{
1 Following the observed neuroscientists, I use the term "subject" neutrally; it refers to human as well as to nonhuman subjects.
} 
I will develop my argument in three steps. I start by describing my project and outlining the theoretical concepts which served as guidelines for my observation and data coding and which acted as a sensitizing concept (Blumer 1954/1986). I then sketch my methods of data collection and interpretation and provide an outline of the general structure of the field, as this influences the presentation of data. In the third section, I present a description of research practices in monkey labs and offer an interpretation of these practices.

\section{Expressivity and Expressive Realization as an Attribute of Positionality}

Neuroscience has created impressive technical tools such as pacemakers for the brain, which can be implanted in the brains of epileptic patients. Furthermore, neuroscientists have developed a fascinating imaging technique. They produce pictures that, they claim, show which regions of the brain are active when we feel, when we perceive other persons, or when we make decisions. It is the aim of many neuroscientists to explain such mental phenomena by reducing them to neuronal events. The crucial step in doing so would be to build an explanatory theory of the brain. Constructing such a theory is therefore a long-term aim of neuroscience, the achievement of which requires particular research strategies. According to contemporary approaches in neuroscience, it is necessary to examine the activity of individual cells, of small cell groups and of the dynamic organization of large neuronal networks. This activity is identified with the brain's internal processing of signals (and information). According to the self-interpretation of the researchers, "invasive electrophysiology" is the branch of research concerned with how the brain processes signals in detail, and it is this kind of research which will lay the groundwork for an explanatory mechanistic theory of the brain. Other types of signals like fMRI do not have the same reputation of being relevant for an explanatory theory of the brain. Changes in blood oxygen level, for example, are evaluated as an indication that energy-demanding neuronal activities have occurred in corresponding areas, which is why more energy has been used and therefore more oxygen consumed. Assuming that this is the case, such a measurement would offer indications as to where to presume increased neuronal activity, but it would tell us nothing about what has actually occurred in these areas.

\section{The Project}

For several reasons, I largely omitted from my project neuroscientific research that employs other signal types than invasive electrophysiology, including, for example, positron emission tomography (PET) or functional magnetic resonance tomography (fMRI), which measures changes in the blood oxygen level. On the one hand, other STS researchers have done extensive studies on these types of signals (Burri 2001; Dumit 2004; Roepstorff 2002). On the other, invasive electrophysiology seems to be the most reductionist branch of neuroscience. Within this field neuroscientists work most rigorously on an explanatory theory of the brain, so that it is of particular interest to look for elements of understanding in the process of experimentation. 
In invasive electrophysiology, an organism has electrodes lowered into its brain. These electrodes detect and transmit the electrical signals of individual cells and smaller cell groups. For ethical reasons such research is not conducted on human subjects for purely scientific purposes, but only on animals. ${ }^{2}$ The most frequently used animal subjects include mice, rats, cats, and macaque monkeys. Macaques are used almost exclusively for the analysis of higher regulating functions, including complex learning processes. This was also the case at the institutes where I carried out my observations.

My project is concerned with two fields of STS which are often separated: research on neuroscience (Borck 2002; Dror 2002; Hagner 2002; Hagner and Borck 2002; Harrington 1992; Hayward 2002; Loettgers 2007; Rees and Rose 2005; Smith 2002; Young 2002) and research on animal experimentation in general. Empirical analysis of electrophysiological experimentation on monkeys seems to fall in a noman's-land between established regions of interest. Scientific studies on animal experimentation focus on experiments on mice and rats and sometimes dogs (Birke et al. 2006; Lynch 1988; Michael and Birke 1994; Solot and Arluke 1997). Where research on primates is of interest, it includes mainly the observation of noninvasive biological research, such as Donna Haraway's (1990) work on primatologists and their research objects, Lawrence Wieder's (1987) study on face-to-face-interactions between primatologists and apes, or Bruno Latour's (1994) analysis of the observation of monkey interactions.

The analysis of a field populated by human as well as nonhuman primates requires a subtle discussion of the actor-status of the entities involved. As mentioned above, nonhuman primates have a reputation for being demanding subjects. Neuroscientists recognize them as actors who contribute to the experiment in a manner differing significantly from the contributions of technical artifacts, as well as from the contributions of the human subjects and experimenters.

Thus far, studies on agency have mainly argued that artifacts should be taken into account. This is the major insight of actor-network theory (Latour 2005) and the concept of "distributed agency" developed by Werner Rammert (2007) and his collaborators. The latter have criticized Latour for his flat concept of agency, asserting that there are various forms of agency. They distinguish between the agency of artifacts and that of intentional self-conscious actors (Rammert 2007). Wieder's (1987) study adopts a similar distinction, namely that between the intersubjectivity of intentional subjects living in the "Lebenswelt" (life-world) and objects. These approaches do not take into account that being alive may constitute a different form of agency. If living beings are considered to display a third form of agency that is not identical to the agency of artifacts or self-conscious social actors,

\footnotetext{
2 This technique is used on human subjects only when electrodes are introduced into the brain for therapeutic reasons, for example in treating people with epilepsy. The electrodes are then used to stimulate certain areas of the brain electrically. However, these same electrodes can also be used "in reverse," that is, to record the electrophysiological signals of neurons. The areas of the brain involved here are not determined according to the criteria of scientific research but rather by those of therapeutic treatment. Research and recording based on scientific criteria in the narrower sense of the term can be conducted only on nonhuman organisms.
} 
it becomes necessary to examine the differences in how inanimate artifacts, living beings, and conscious or self-conscious beings cause effects (Lindemann 2007).

Actors, Representations and the Theory of Positionality

In order to gain a fuller understanding of these differences, I draw on to the theory of "positionality" developed by the philosopher and sociologist Plessner (1928/ 1975) in his book Die Stufen des Organischen und der Mensch [The Levels of the Organic and Man]. In terms of methodology, Plessner generalizes the use of a second-person perspective. Usually a second-person perspective is adopted in order to understand social phenomena, symbolic interaction (that is, the events among the members of a "symbolic species") or symbolic communication, as Roepstorff (2001, pp. 747, 762) puts it, drawing on Ernst Cassirer. Plessner extends the use of the second-person perspective. He applies it to beings which do not use symbols but are simply alive or are simply conscious. Understanding symbols or understanding interactions mediated by symbols is only one form of understanding. According to Plessner, the most basic event to understand is the event of being alive.

Plessner uses the term positionality to denote the capacity of living things to realize their own borders, a quality which distinguishes them from inanimate things. A living being delimits itself from its environment and mediates all of its contact with that environment through these self-drawn borders. Living beings regulate their contact with their environment and maintain themselves vis-à-vis that environment as self-organizing entities. Plessner thus asserts that biologically observable and experimentally determinable phenomena must also be comprehensible in terms of positionality theory. If this is the case, we can, conversely, also regard such biological phenomena as the realization of being alive. Plessner views expressivity as coming into play even at this level. Living organisms produce their own borders - a fact that is evident on or in the organism itself and can therefore be observed. The production of one's own borders is an expressive phenomenon insofar as being alive is not strictly identical to the produced phenomena, which can be observed directly. According to the theory of positionality, the observed phenomena must be treated as indications of the fact that the organism is alive. In other words, the reason to interpret phenomena is that they are an indication of the activity of life, which appears only indirectly. The fact of being alive has to be concluded from the observed phenomena.

A further complication arises for living things that possess consciousness, or, in Plessner's words, that exist on the level of "centric positionality." According to Plessner, conscious living beings are able to relate to the fact of their border realization and can therefore regulate their external appearance independently. We can distinguish here between two dimensions of this relationship to the living being's environment: perceiving the external field and affecting the external field. Both of these dimensions are realized expressively. The organism appears as a being that perceives and affects. We should not equate expressivity solely with affecting, as perceiving is also realized expressively. Thus, through observation we are able to determine that an organism, first, perceives its environment; second, affects its environment; and third, mediates between these. How an organism coordinates this 
perceiving and affecting is left to the organism itself. As part of this process, an organism develops expectations regarding the future course of events and acts in accordance with these expectations. To the extent that an organism regulates itself in this way, it alters its own appearance according to its inner state and thereby regulates its own expressivity. For Plessner, understanding a conscious organism makes reference to its inner states and to how it regulates itself based on its relation to the environment.

"Excentric positionality" designates a situation arising from the performance of self-regulation, in which an organism is able to distance itself from this performance and is thus capable of relating to it. On the level of excentric positionality, an organism is able not only to develop expectations and regulate its behavior accordingly, but also to relate itself to its own performance of self-regulation. In other words, it can comprehend itself as an organism that other organisms develop expectations about. Excentric organisms adjust their own behavior according to the expectations others have of them. For excentric organisms, the environment is also populated by other expecting organisms, whose expectations must in turn be expected. When referring to the circumstance of organisms existing in this kind of mutual relationship I use the term "personale Vergesellschaftung" (Lindemann 2006). It may be translated as "sociation to social persons". Thereby I mean that a being becomes a social person within and by the process of sociation. This circumstance must also be realized expressively. ${ }^{3}$ There is, however, a further, and decisive, feature we must consider here. If sociation to social persons is realized expressively, it can only be observed in the relation of organisms to one another. Excentric positionality and sociation to social persons cannot be realized by an individual organism alone.

Excentric positionality and sociation to social persons refer to relationships which show a structure similar to that of the social relationships of intentional and self-conscious actors described by Rammert. He distinguishes this form of agency from artifacts. Wieder (1987) distinguishes between the intersubjectivity of the "Lebenswelt" (life-world) and the relation to objects. Such a distinction takes into account only excentric beings and objects, omitting other forms of being alive. Using Plessner's theory, it is possible to distinguish social actors from any other form of agency which implies consciousness and simple expectations. Yet there may be another form of agency of living beings: simply being alive. We can now differentiate these forms of agency from the agency of inanimate artifacts; that is, from entities which cannot die and which are not considered to have expectations. Artifacts are assumed to break down, but they are not assumed to display an autonomous activity which ceases such that it would be meaningful to describe the process as dying. Referring to Plessner allows us to develop a highly differentiated concept of agency, which is neither flat (like Latour's) nor dichotomous.

\footnotetext{
3 "Centric" and "excentric" are technical terms introduced by Plessner, in order to describe different forms of how beings relate to their environment. A relevant quality of excentric organisms is that they are mind-reading organisms which assume that their own mind is also read. For a discussion of a sociological-interaction approach in comparison to "theory of mind," see Bohman (2000). See also Lindemann (2005).
} 
Plessner's theory provides a fresh perspective in another respect as well. Rheinberger (1992a, p. 80f) has offered an intricate analysis of representation in science. He shows that far from representation being a means of portraying a preexisting reality, the experimental process produces the represented reality. In these terms, brain activity as it occurs in neuroscience would be conceived of as an epistemic object which is not external to representation. On the contrary: the experimental system would be the condition of existence of brain activity as an epistemic object. The brain as an epistemic object is represented by traces produced by recording devices, but these traces do not represent nature. Instead, it is the experimental system which produces brain activity as an epistemic object by representing it as traces. ${ }^{4}$ Applying Rheinberger's framework, the process of representation refers above all to the activities of neuroscientists and artifacts. But there is another actor in the field: the monkey organism. Plessner's theory demands that we always ask: What is the role of the living organism in the experiment? What is the significance of its expressivity? Are there indications that its expressivity has to be understood?

This question has been more or less neglected conceptually in the analysis of laboratory life. The field studies of STS that have been conceptually influential (Latour and Woolgar 1979) focused on sciences that were not concerned with living organisms. Sometimes the organism played some kind of preliminary role. It had to be killed, some of its parts becoming an epistemic object only after its death (Lynch 1988). My data suggests that in many fields of neurobiology, the living organism cannot be transformed completely into a technical and/or epistemic object. The experiment is chronically concerned with the present activities of the living organism. It is only during the final stage of data analysis that neurobiological experimenters can create an epistemic object.

\section{Methods: Diplomacy, Participant Observations in Monkey Labs and Data Interpretation}

Let me turn now to the world of monkey research and its interpretation by the involved social persons. The field is structured by an intense political conflict. The overt opponents are scientists and animal rights activists. They live in a state described by Deborah Blum (1994) as "Monkey Wars." Compared to this conflict, the so-called "science wars" resemble a pleasant kaffeeklatsch among friends. Animal rights activists articulate their critique not only through words, but also by such actions as anonymous phone calls during the night, threats of kidnapping the children of involved scientists, or throwing Molotov cocktails into labs or placing them in front of a scientist's home. Therefore many neurobiologists hold that animal rights activism is the most dangerous homeland terrorism in the US. Scientists

\footnotetext{
${ }^{4}$ For an analysis of visualization techniques, see also Ihde (2006) and his concept of revolutionary visualizing techniques.
} 
support tough political action against animal rights activists. ${ }^{5}$ Animal rights activists themselves take a different stance on these political actions. They see them as a form of criminalizing even the most peaceful critics of animal experimentation.

As Michalowski (1996) has pointed out, the broader political context of an ethnography can be influential to such a degree that it is necessary to give an account of it for methodological reasons. The conflict between animal rights people and neuroscientists had not only an impact on data collection but also has shaped the presentation of data in this article. For my research, I had to involve myself in particular with the scientists' side. In order to obtain access to a monkey lab, a sociologist must first establish trust. Not least, this means convincing specific scientists that the resulting sociological publications will not cause any harm to them or to monkey research in general. The question of what descriptions will be considered too negative is hard to answer beforehand. Every word will be caught in the conflict and weighed by both sides. Therefore this text does not contain any picture of the experimental settings. Pictures are major means of monkey wars. They are supposed to have a strong emotional appeal. Scientists believe that lay persons looking at a monkey prepared surgically for neurobiological experiments would be appalled. ${ }^{6}$

In order to make sense of this situation, I refer to Niklas Luhmann's (1984) communication theory. He has pointed out that the meaning of a message is constructed communicatively; it is not only what a speaker intends to say but how it is interpreted by others that is important. Whether my description communicates a too positive or too negative description of monkey research will be decided by other persons in the process of communication. The only way for me as the writer to negotiate this situation is to anticipate the expectations and attitudes of my prospective audiences. Thereby my writing is guided by the expectations of expected audiences.

As the article cited in footnote 6 shows, the use of pictures would always be considered as a kind of negative judgment. Even every kind of verbal description which appeals to emotions in a remote way would be considered as such. Therefore I adopt a dispassionate style, which is inspired by the abstract and formal conceptualization of subjectivity formulated in the theory of positionality. This strategy does not deny that the experiments are performed on subjects feeling their own states,

\footnotetext{
5 To give the reader a taste of the atmosphere, I recommend Donald Kennedy's (2006) editorial in the journal Science. That it is problematic to describe animal experimentation practices is not a new phenomenon. It was even a problem for biomedical researchers themselves. See Susan Lederer (1992).

${ }^{6}$ I quote from an article in Die Zeit, a weekly German newspaper addressed to educated people. The article is based mainly on an interview with a neurobiologist from the University of Bremen, Andreas Kreiter. The text is strongly in favor of invasive experimentation with monkeys. It includes a paragraph on the problem of publishing pictures. I give a loose translation: "It is permitted to take pictures only of those monkeys whose heads are undamaged. If a lay person looked into the face of a surgically prepared monkey, he or she would see the monkey as a human, and would be so appalled that all attempts to explain would fail ... the pictures are so strong." The original quote is: "Von den 23 Laboraffen dürfen nur diejenigen fotografiert oder gefilmt werden, deren Kopf unversehrt ist. Denn wer als Laie einem der operierten Affen ins Gesicht blickt, sieht darin die menschlichen Züge - und gruselt sich so sehr, dass jeder Erklärungsversuch scheitern muss. Mit diesem Ergebnis ist auch ein persönlich mit Kreiter befreundeter Dokumentarfilmer wieder abgereist. 'Die Bilder sind so stark, dass sie alles andere überdecken', habe er ihm zum Abschied gesagt, erinnert sich Kreiter.” (Die Zeit, No. 17, p. 39).
} 
having their own preferences, etc., but at least it tries to avoid spontaneous identification either with research subjects or experimenters, respectively.

After this sketch of the field as a whole, I will give an outline of my concrete methodological procedures. Between 2004 and 2006 I conducted field work for extended periods in several research institutions in Germany and the US amounting to 11 months of participant observation in different labs. I also conducted around 30 expert interviews with neuroscientists, lab technicians, veterinarians and animal caretakers. Most of this time was spent in monkey labs. I additionally participated as an experimental subject myself in some trials and recorded my experiences.

The interviews were paraphrased or transcribed. Both the field notes and the interviews were coded. The coding procedures can be described as a heretical deviation from grounded theory. According to Anselm Strauss, the code should be developed primarily with reference to data alone (Glaser and Strauss 1967). However, as I already mentioned, I used not only the data but also an abstract theory as a point of reference for coding. That is, the coding of the data was structured by a double perspective. Concepts such as expressivity or the difference between, on the one hand, centric positionality/simple expectations and, on the other, excentric positionality/expectation-expectations structured my coding.

The major problem with such a theory-guided approach is the production of conceptual artifacts-i.e., data-which, due to the adopted theoretical framework, are only produced in the field notes. This danger cannot be avoided, but it should be controlled by making one's theoretical assumptions as explicit as possible. I call this a critical-reflexive method (Lindemann 2002). It is critical insofar as it assumes that observation and interpretation is structured by theoretical concepts. By explaining them, the observer gives a self-critical delimitation of how s/he will construct his/her observations and interpretations. This aspect may be somewhat unusual for sociologists. The second aspect is commonplace. Sociologists expect that they are confronted with actors who interpret the world themselves. Sociologists expect to be confronted with an already interpreted world. They therefore see themselves as confronted with the task of reflexively working out interpretations of interpretations. ${ }^{7}$

As I said, the production of data and its analysis are theory-driven. This is quite uncommon in qualitative research and leads to a theory-oriented presentation of data. My account is structured by the following hypothesis.

According to the self-understanding of the involved scientists, electrophysiological research provides a mechanistic account of the brain and its functions by using a third-person perspective. ${ }^{8}$ An explanatory theory of mental phenomena like attention, memory or decision making will thereby be achieved. I suggest that it is impossible to give a valid account of the experimental process as long as only a

\footnotetext{
7 I will not go more into detail here, since this part of sociological methodology is to some extent common sense. Georg Simmel pointed it out first in 1908 in his Sociology. Later on Alfred Schutz emphasized that sociologists always interpret the interpretations of the observed social actors. Anthony Giddens presented the same insight, and Latour applied it to the problem of who can count as a social actor.

${ }^{8}$ Wolf Singer, one of the leading neuroscientists, who is also engaged in discussions with philosophers, states this in several publications. See, for example, his essays in Singer (2002).
} 
third-person perspective is adopted. A close examination of the research process instead reveals that, in practice, neuroscientists adopt a "second-person perspective." They treat their counterparts as expressive beings that to be handled must first be understood. ${ }^{9}$

Understanding the expressivity of others is usually used as a framework for the analysis of social persons. We expect that our counterpart is not only a physically perceived entity, but also a meaningful one. By this we mean that there is a self, which expresses itself, its intentions and expectations, through gestures and speech. This can be described as a "second-person perspective," which is predominant in social science theory and methodology (Bohman 2000). ${ }^{10}$ In terms of methodology, Plessner's approach is characterized by the adoption of the second-person perspective for the analysis of biological phenomena (Lindemann 2008).

\section{Experimental Practices}

In neurobiology, experiments last much longer than, for example, in molecular biology. The whole process from designing the experiment to data analysis and publication can take up to $4-5$ years.

An experiment is conducted in four stages:

1. Designing the experiment

2. Integration of the subject into the experimental arrangement; in the case of monkey subjects, this includes learning the task

3. Recording neuronal activities while a subject performs the task

4. Preparing and analyzing the data

\section{Stage 1: Designing the Experiment and Preliminary Procedures}

I describe the concrete design of experiments only sketchily, as a detailed description of scientific questions and the construction of experiments would enable a reader to identify individual labs. Based on existing knowledge, a research question is more or less precisely defined and a target area identified. For example: Which brain area's neuronal activity is relevant for short-term memory, motor control or visual perception (or even more specifically: for perception of color or shape)?

The identification of a target area is based on existing neurobiological knowledge. Different areas of the brain are considered to serve different functions. The input from the stimulation of different sensory organs (eyes, ears, etc.) is processed in different areas of the brain. Giving an emotional value to perceptions or starting and controlling a motor reaction are mainly controlled by different regions. The idea of spatial organization furthermore implies the distinction

\footnotetext{
9 Roepstorff (2001) has argued that a second-person perspective is relevant to the experimental process with human beings. My argument goes a step further, as I try to show the practical relevance of the second-person perspective for the experiments with monkeys.

${ }^{10}$ For an empirical description of the methodological consequences, see Lindemann (2005).
} 
between "bottom-up" and "top-down" processes. Bottom-up processes are driven by the stimuli coming in. Reference to bottom-up processes only, however, is not sufficient in order to gain an understanding of perception.

The problem is that each retinal image could have arisen from any of a vast number of possible 3-D scenes. That we rapidly perceive only one interpretation tells us that we see far more than the immediate information falling on our retina. The highly accurate guesses and inferences that we make rapidly and unconsciously are based on a wealth of knowledge of the world and our expectations for the particular scene we are seeing. The influences of these sources beyond the images on the retina are collectively known as topdown influences. (Cavanagh 1999, p. 844)

Again, in neuroscience bottom-up and top-down processes are associated with different areas of the brain. If a researcher wants to understand the early phases of the bottom-up process of visual perception, s/he has to lower electrodes into a particular area of the brain. If it is the top-down process that is of interest, the target area will be a different one. Often the target area is called the "region of interest." With reference to Rheinberger's distinction between technical and epistemic objects, a region of interest shows properties of both. Because the way in which neuronal signals are processed is assumed to be known, electrodes of a certain shape and sensitivity must be used. A technically stable connection must be established between the cells of the region of interest and the measuring and storing devices. This connection has to function in the same way again and again. In this sense, the region of interest has the characteristics of a technical object (Rheinberger 1992b). On the other hand, it is unknown which events will occur, and which pattern of neuronal activities will be detected in the region of interest. The brain, and in particular the region of interest, will be transformed into an epistemic object when the recorded data is analyzed.

\section{Stage 2: Integration of the Subject into the Experimental Arrangement}

Integrating a monkey subject into the experimental arrangement is a complicated interaction process. In particular, two aspects are important here: First, during this phase the monkey is recognized as a conscious organism which has to be motivated to participate actively in an experiment. Second, the monkey exists not only as an organism, but also as a technical object which can be connected to several technical devices in order to perform the experiment. Both aspects are of crucial relevance for an understanding of the integration process.

The living conditions of laboratory monkeys differ from lab to lab. Despite these differences, some generalizations seem possible. In a typical US lab monkeys are housed either by themselves in a cage or in pairs. A single-housed rhesus monkey lives in a cage roughly $0.9 \mathrm{~m}^{2}$ in floor area and $1.8 \mathrm{~m}$ in height. In the case of pairhousing, two of these cages are connected, allowing the monkeys to move from one cage to the other. About six pair-cages are usually placed in one large room. Monkeys can interact by gaze, gestures and sound. In Germany there are a number 
of labs which offer different housing conditions: The monkeys live in groups of 2-6 individuals in spacious room-like cages, the sides of which are an estimated 3-4 m in length and height.

Regardless of how rhesus-macaques are housed, they expect to know whether an interaction partner is superior or submissive. Questions of power and hierarchy dominate their perception of relationships. This is true in both pair and group interaction. According to members of the veterinary staff, a hierarchy is established even in the larger rooms with either single- or pair-housed monkeys.

\section{The Monkey in the Chair}

The first step in a subject's integration into the experimental arrangements is to get him/her into a so-called "monkey chair" or "restraint chair." According to the necessities of the experimental design, a monkey chair restricts the subject's movements. A very common device is a metal collar around the neck of the monkey. The collar can be connected to the chair. Some experimenters do not use a collar. Then the subject's body is enclosed in a Plexiglas box with only its head protruding from the top. The initial steps of familiarizing the monkey subject with the experimental setting are done either by a lab technician or by an experimenterusually a PhD student.

In the US, a monkey subject unfamiliar with restraint chairs, laboratories and experiments is called a "naïve monkey." I have not heard a similar expression used in German labs. But the problems which occur seem to be similar. Monkeys are described as more or less "neophobic," as they like their routines and dislike surprising changes. ${ }^{11}$ It is a long, step-by-step process in which a subject learns to leave the cage, be moved into a chair, be brought from the monkey room to the lab where the experiment is to take place, and finally learn the task and work for hours in an experiment. It should always be the same person who handles the monkey. Usually two, or at most three persons are involved. Every step in this learning process is rewarded, either by giving the monkey fruits, nuts, raisins, etc., or by administering liquids (water or juice). The first lesson the subject must learn is that it is the experimenter (or the lab technician) who provides these fluids and delicacies.

A lab technician describes how he gets a monkey into a restraint chair:

The first step is to go into the room, so the monkey gets used to the presence of someone new. I feed him fruits, candies and treats. The animal becomes accustomed to the presence of the new person. Once the monkey has grown familiar with the new situation, he is anesthetized and fitted with a collar. The next step is to hold a pole into the cage and latch the pole to the collar. When the monkey becomes anxious, he again receives fruits, candies and treats. When he comes to tolerate it, he ${ }^{12}$ is taken out of the cage. At this point, the

\footnotetext{
11 Some scientists describe this as a common feature of primates - implicitly and sometimes explicitly including human primates as well.

12 At most of the institutes I observed, the Macaque monkeys were referred to as a "he" or a "she" and not as an "it."
} 
whole community of monkeys intervenes. When a monkey is taken out of the cage, all the other monkeys will look at him. The monkey becomes anxious. To calm the monkey and make him 'confident in the process,' I offer fruits, candies and treats to all the monkeys in the room. The entire process up to the point described takes from one week (extraordinarily fast) to one month (extraordinarily long). Then the fruits are placed in the chair. One has to pull the monkey into the chair 'gently but firmly.' Usually we are stronger than a monkey. ... It takes 5-10 minutes. Once the animal is in the chair, it gets something special, again fruits or something. (Fieldnotes)

I have chosen this description because the cited lab technician, Bill, describes his interactions with a monkey in an objectified manner. Other lab technicians or experimenters describe monkeys as subjects with highly differentiated feelings and thoughts, and sometimes they use anthropomorphisms. ${ }^{13}$ Despite his objectifying attitude, the lab technician understands the monkey explicitly as a being who perceives his environment, experiences his own states (he may be anxious), and acts according to his perceptions. Furthermore, the monkey is treated as a being with expectations. The subject is used to a routine, that is, s/he has developed concrete expectations concerning the course of events. Even the occurrence of a new person in his environment is considered a breach of his expectation pattern. The subject has to learn that the new situation is not harmful. Step by step, s/he has to develop new patterns of expectations.

I interpret this account as an indication of the lab tech recognizing the monkey as a conscious being. It is not an ascription which can be withdrawn voluntarily. For all practical purposes, the monkey must be recognized as a conscious subject by the lab technician and/or by the experimenter. The methods adopted by other lab technicians or by experimenters differ in detail. I found no evidence, however, to suggest that for practical purposes a lab technician or experimenter does not recognize a macaque subject as a conscious being-expecting a certain course of events and regulating his/her own relationship to the environment.

The second aspect of the monkey being treated as a technical object becomes obvious by looking at the surgical preparations of the monkey's head. Determining the region of interest in a individual monkey brain means determining where a socalled "recording chamber" will be implanted on the skull. A piece of the cranium must be removed under sterile conditions equivalent to those in neurosurgical operations on human beings, leaving an opening approximately $1.5-2.0 \mathrm{~cm}$ in diameter. The recording chamber is then placed in this opening. An electrode matrix can be attached to the chamber and rendered immovable. (Usually the matrix is only placed on the chamber during recording sessions and removed after recording. $)^{14}$ The recording chamber is implanted in such a way that the regions of interest are easily accessible by perpendicular entry of the electrodes into the brain.

\footnotetext{
13 I quote from my field notes: "In a discussion how to treat a particular monkey, who has a reputation for being a difficult experimental subject, the PhD student who works with her argued: 'Judith is a lady. You have to respect her. You have to ask for her permission when you invade the space around her.'”

14 Sometimes electrodes are implanted chronically.
} 
In order to ensure that the activities of the same cells or cell groups are recorded consistently, the electrodes must stay in absolutely the same position throughout. Presumably, an organism would not sit as still as is required. The recording chamber must be placed on the skull such that a head post can additionally be attached to the monkey's head. The post serves to mechanically fix the head during the experiment. The head post is the first indication of the necessity of chronically transforming the organism into a techno-epistemic object.

A third preliminary procedure is the implantation of an "eye-coil" in the subject to permit the measurement of eye movements. The surgical procedures are usually described in detail in the methods section of neuroscience papers. ${ }^{15}$

\section{The Monkey in the Chair Facing a Task}

The next steps are to familiarize the monkey with the lab itself and to get him/her to learn the task. The latter consists of two parts: First the chair is placed in a box, which serves as a faraday cage, in front of a monitor. Now the subject must learn to treat the events displayed on the screen as a problem, the solution to which requires him/her to take action. Second, the subject has to learn to work for an extended period (= 3 to 4 hours). This learning process is called "training." A monkey who is trained "works." A monkey who performs many consecutive trials without a break is "a good worker." To illustrate these terms, I will describe two different tasks in more detail.

The "delayed match-to-sample" task is a variable experimental design frequently employed in monkey labs worldwide. This experiment involves presenting a subject with two visual stimuli in short succession. The first of these is the "sample stimulus," for instance the image of a banana. The second, the "test stimulus," presents either the same image — a banana again_or another image, for example a cherry or an umbrella. If the same image appears, there is a match, or correspondence, between the test and sample stimulus. If a different test stimulus is presented, there is a non-match, or non-correspondence. The monkey's task is to indicate through his/her behavior whether s/he has comprehended the difference between a match and a non-match. The macaque is presented with various options, depending on the experimental design. In one variant the subject can press two different buttons (for example, the left one for a match and the right one for a nonmatch). In another, s/he takes hold of a lever at the beginning of each trial and releases it only when there is a match. Each of the individual sequences lasts only a few seconds and is repeated hundreds of times every session. Well-trained laboratory monkeys are capable of engaging in up to two thousand individual trials per session. For each correct answer, the subject receives a reward in the form of a drop of water

\footnotetext{
15 "Two rhesus monkeys (Macaca mulatta) weighing 8-9 $\mathrm{kg}$ were used. Prior to the implantation of the recording chamber, the animals were placed in a plastic stereotaxic machine and scanned with magnetic resonance imaging (MRI). A head restraint post, recording chamber, and scleral eye coil for monitoring eye position ... were implanted under aseptic conditions while the animal was anesthetized with sodium pentobarbital. Using the coordinates derived from the MRI images, the recording chamber was centered on the dorsal surface of the skull above anterior-ventral IT and oriented in the Horsley Clark stereotaxic planes. The animals received antibiotics and analgesics postoperatively." (Miller et al. 1993).
} 
or juice. The sequence within each individual trial as well as the succession of individual trials in a session is timed in milliseconds. The reason for this is that signal processing in the brain is assumed to occur at a comparable or even greater velocity.

Whereas the delayed match-to-sample task is concerned with higher cognitive functions, the second design is focused on elementary bottom-up processes of visual perception.

The subject is confronted with three different conditions. Condition 1: Stimulation of cells of the early visual cortex. The subject receives a drop of water or juice if s/he reacts to the stimulation, that is, if s/he 'detects' it. Condition 2: No stimulation is administered. The subject has to sit and wait. Condition 3: A figure ('target') is displayed on the screen. The subject receives a reward if $\mathrm{s} / \mathrm{he}$ detects the target and hits a lever. (Fieldnotes)

Nobody other than the monkey knows whether the stimulation makes a difference in his/her experience. Therefore it is crucial that s/he answers "honestly." The aim is to find out which cells react at all, and to what kind of stimulation. Conditions 2 and 3 are control conditions. If the subject hits the lever too many times without receiving stimulation, this is interpreted as reacting randomly and inattentively. If this happens too frequently, a series of external visual stimuli are presented which the subject is supposed to detect. If s/he answers correctly, the experimenter will again present a series of conditions 1, 2 and 3. If the monkey does not react to condition 2 and correctly detects the targets of condition 3, his/her answers to condition 1 are interpreted as being honest. One experimenter describes the problem thus: "I have to keep her honest."

In the process of learning a task, a monkey is treated as a conscious being. Even interpreting the monkey's behavior as an expression of emotions becomes practically relevant. The events of a training session are recorded in a "training book." In the beginning, some experimenters give rich descriptions of their experience with their monkey. With regard to Catherine, the experimenter notes: "If I try to help her, she gets angry. She can figure out for herself which button to press." The initial training consists of the experimenter taking Catherine's "paw"16 in order to show her what she is expected to do. Catherine reacts angrily. This ascription of an affective state presumably means that she threatened him and tried to scratch him. In this case, the interpretation of Catherine's affective state becomes practically relevant. In principle, it would have been better if the experimenter had continued to train her, but for this session he let her work on her own.

The Monkey in the Chair Working for a Reward

Learning the task is a complicated interactive process in which the reward the subject is given has a dual significance. It is through the reward that the subject is induced to participate in the experiment at all. However, the reward also has a cognitive-interactive function.

\footnotetext{
16 "Paw" is the word used by the experimenter.
} 
Regarding 1: By and large, macaque subjects are not motivated to take part in the experiment of their own accord. Their interest in participation must be induced in a secondary manner. During the work period they are given no fluids as part of their daily diet. In the researchers' jargon, the macaques have to "earn" their fluids through participation in the experiment. In the eyes of the experimenters, deprivation of fluids does not constitute a negative sanction but instead increases their receptivity for positive reinforcement. The experimenters strictly reject negative reinforcement, that is, punishment. Although deprivation of fluids is a drastic measure, it does not have a mechanical effect in the sense of unambiguously altering behavior. It is left to the monkey subjects whether and to what degree they are motivated by this measure to participate in the experiment.

The work period is differently structured in the US and Germany. In Germany it is a regular workweek from Monday to Friday. During the workweek monkeys have to earn their liquids. From Friday after work until Saturday they have free access to water. In the US institutes the work period lasts for 10 to 12 days. The goal is not to work along the lines of a foreseeable schedule.

John explains why he does not use a weekly rhythm: If monkeys get water from Friday to Saturday, they don't work on Mondays and Tuesdays, and on Fridays it becomes a problem too. They can predict that they will receive water and fruits soon. Therefore, I try to make it not so predictable. I prefer a 10-day rhythm. (Fieldnotes)

The general rule in his lab prescribes that a monkey should have free access to water for three days every four weeks. It is the experimenter's decision when his/her monkey has free access to water. Regardless of how much a monkey works, s/he should receive a certain amount of liquid (depending on his/her weight) every day.

Occasionally a subject sits in a chair in front of a stimulus and does not work. When discussing possible solutions, scientists and lab technicians take into account the fact that a subject does not react only to the stimulus in the lab. In order to understand why a subject is not motivated to participate in the experiment, scientists and lab technicians always refer to the situation of the subject as a whole. As a starting point, they take the behavior exhibited by the monkey. Lack of motivation can be caused by restraining devices. The experimenter will examine them and check whether they could make the subject feel too uncomfortable, and whether adjusting them helps to increase the monkey's motivation. If the subject does not display any signs of distress, s/he will be suspected to have fallen back on other sources of liquid. This opportunity may be offered by the conditions of housing. As I have mentioned, some monkeys live in groups in spatial cages which are cleaned with water. Finally, a subject can try to drink as little as possible.

In American research institutions, a monkey has the choice between working and waiting for water or juice, because the monkey can expect to receive water anyway. Although different experimenters use different strategies, everyone has a strategy for handling the situation. Some experimenters argue that a monkey should not receive water in the lab without working for it. Others believe, it is better that a monkey only receive water or rewards in the lab, so that the monkey associates rewards with the lab rather than the monkey room. 
These strategies for making the monkey work in the experiment display a practical sense of the monkey as a subject that mediates its own states with its perception of its situation. Although the monkey is made thirsty by rather rigorous methods, no one believes that his/her behavior is simply externally determined. On the contrary, the monkey is supposed to have a choice in how to react to the situation.

This becomes more obvious when other reasons are discussed. If a subject not only works poorly but is anxious or somehow agitated, it is an indication that the monkey is having trouble with cage-mates. Researchers discuss, in accordance with their interpretation of the monkey's situation, how s/he can be efficiently motivated to resume untiring and focused participation in the training or the experiment. If the social situation is believed to be the problem, it is exhaustively discussed: Which individuals are compatible with which others? Which individuals would fight with each other, etc.? Especially in the case of group housing, falsely estimating relationships among macaques can have severe consequences, since their fights can lead to serious injuries.

If an organism is treated in this way, s/he is recognized as a conscious being. As such, the macaque subject cannot be controlled directly, but itself steers how it is controlled by the external means. It therefore seems appropriate to assume that the macaque subject is expected to follow a motive. It is up to the macaque to decide whether s/he allows him/herself to be motivated.

Regarding 2: Beyond this function, the controlled administration of fluids also works to permit a clear interactive understanding on the behavioral level between subject and scientist. Scientists expect that, within an extremely controlled situation, the macaque subject will regard a sequence of images on a monitor as a task to be accomplished. It is impossible to explain this to the subject verbally, but must be demonstrated by giving or withholding a reward. Since the macaque subject is almost certainly thirsty, s/he is supposed to be interested in fluids and in anything that will result in him/her receiving them. Whether the subject is able to perform the cognitive task is then demonstrated through his/her behavior. Pressing a button or releasing a lever indicates the subject's response to the image sequences. If subjects react randomly, their behavior is evaluated as non-comprehension. For example, one experimenter assessed the situation as follows: "He doesn't understand yet." If, in contrast, the subject does not press the buttons randomly but in the desired manner, the monkey has demonstrated that s/he understands what is happening. Conversely, administering the reward demonstrates to the monkey that s/he has performed correctly.

I ask Ms. Miller (laboratory technician), 'Why don't you wait until the monkey has answered correctly four or five times? Then he could receive more water at once instead of a small drop for each correct answer.' Ms. Miller, 'That's not possible. How would the monkey know that he has answered correctly?' (Fieldnotes)

For a macaque subject to be admitted to the actual experiment, three conditions must be fulfilled: (1) The subject must demonstrate that s/he has understood that the sequence of images or other stimuli is a task to be accomplished. (2) The subject must 
demonstrate through his/her answers that s/he understands what is happening. (3) The subject must demonstrate a continuous readiness to participate in the experiment. If any of these three criteria is not met, the subject is not admitted to the experiment.

\section{Stage 3: The Experiment}

The actual experiment begins-like the training before-with the subject being fixed in the chair. Then the electrode matrix has to be placed on the recording chamber. The subject is presented with the stimuli and performs as it has been trained to do. During an experimental session a subject performs up to 2,000 single trials. While the monkey is performing, the experimenter lowers electrodes into the subject's brain; s/he does not notice this, as the brain tissue is not sensitive to pain. The exact positioning of the electrodes is carried out according to sound. This is possible because neuronal activity is represented through both visual and auditory means. Visually, the neuronal activity of several cells - the local field potentialsappears as an irregular curve that flickers on a monitor-an "oscillator." The activity of individual cells is represented as a succession of discontinuously illuminated dots, which can also be depicted as sound. The auditory representation of neuronal expressivity is similar to the static on old shellac records. In the cracks and groans, trained listeners can identify "spikes," the discontinuous signals of individual cells. The electrodes are in the correct position when they transmit the activities of individual cells, that is, when a trained listener hears "spikes." In this way, the organism acquires a new technically mediated expressive surface: It exhibits behavior (eye movements, pressing buttons, moving levers) and neuronal activity (spikes, local field potentials).

One of the crucial problems of electrophysiology is avoiding 'artifacts'. An artifact is a trace which an experimenter does not consider to be produced by brain activity. Sometimes traces are produced by the experimental system itself. Sometimes the electrodes, which are extremely sensitive devices, record the changes in voltage of an electrical outlet. The switching on of the light may even be recorded. A group leader, an accomplished neurobiologist, described it in this way: 'Electrophysiology is the art of avoiding artifacts.

Sometimes the rest of it has something to do with the brain.' (Fieldnotes)

The art of avoiding artifacts consists primarily in debugging the experimental system. Ideally, the scientist should be in control of every event produced by this system. A bug which simply no longer occurs is not the ideal outcome. One scientist described it as "frustrating. As a scientist you always want a reason." (Fieldnotes) $^{17}$

A system is usually extensively debugged before an experimental session starts. Nonetheless, there are things that cannot be done beforehand and so are left to be done at the beginning of a "recording session." The electrodes must be routinely

\footnotetext{
17 I will not go into the details of the technical problems of recording signals. The original signal has to be amplified and filtered. The signal's shape is finally constructed according to the principles of the Niquist theory.
} 
checked for their insulation and their shielding has to be grounded. Good insulation prevents electrical currents running through one electrode from influencing the recorded signal in an electrode next to it. This undesired phenomenon is called "cross-talk." Grounding the recording device prevents interference from external sources such as the power supply.

An experimental system consists of the integration of the following functions: first, presentation of stimuli; second, recording of the behavior of the monkey, such as eye movements, reactions to stimulus presentation (with button or lever); third, recording of neuronal signals; fourth, administering of a reward or not; fifth, storing of the recorded behavioral events and neuronal signals; sixth, signaling that a new stimulus presentation can start. The software guiding the process is usually written by scientists themselves.

Due to these complicated technical procedures, an experimental session usually lasts much longer than a training session. Depending on any technical problems encountered, an experimental session can take from 5 to $9 \mathrm{~h}$. The number of trials a monkey is supposed to perform during such a session depends on the design. From several hundred to 2,000 single trials are possible within most experimental designs I observed. The number of single trials is determined by the necessities of statistical analysis.

In order to prepare this data for further analysis, measuring devices are constructed such that they produce traces which are electronically stored. Certain curves indicate the movement of the eyes. Other curves indicate the local field potentials and discrete dots indicate the rates of spikes. In the neuronal data, the onset of stimulus and the time of the subject's response (pressing a button, releasing a lever, etc.) are marked.

\section{Stage 4: Data Analysis}

The process of data analysis consists of four steps: first, sorting out the remaining artifacts and evaluating the data's quality; second, organizing the data in sets; third, transferring the data into an artificial multidimensional space and analyzing it; fourth, writing, discussing and publishing a paper.

If an experimenter is not a master of the art of avoiding artifacts, it is nearly impossible for him/her to find signals which are good enough for analysis. There should at least not be too many artifacts remaining. For my analysis, it is important that neuroscientists distinguish strictly between traces which are caused by biological brain activity and those which are produced either by an experimental system itself or by external electrical smog. They think of themselves as looking for a representation of brain activity itself. Therefore, one should be careful to apply Rheinberger's concept of the epistemic object. Although the signal is technically constructed, the whole idea of "recording" would be meaningless without a representation of factual neuronal occurrences themselves.

An important criterion for the distinction between artifacts and biological data is "irregularity." A curve that is too regular is seen as being "unbiological." It is an indication that the signal comes from an external source, such as an electrical outlet. 
The curves below show the differences between bad signals and good signals, the latter being irregular enough with regard to their amplitude and frequency.

The following picture shows the data from four different electrodes. The numbers below the curves show the elapsed time in milliseconds.

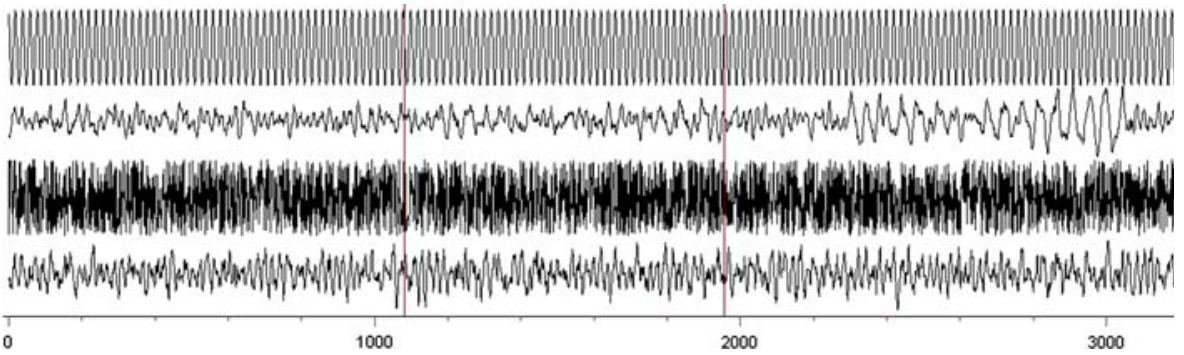

The first two lines give a good impression of the difference between an artifact signal (first line) and a good biological signal (second line). The first line is an example of an overly regular signal-a neuroscientist described such a signal to me as a "signal from the wall outlet."

The second line shows a "good biological signal," a so-called "local field potential." Especially its modulation between millisecond 2,300 and 3,200 makes it a valuable signal.

Lines three and four show two signals, distinguishing between which causes more difficulties. The signal of the third line is read as a random signal, which is hard to interpret, whereas the fourth line shows an unmodulated local field potential. The criterion for data-sorting is always the same: The signal must be irregular enough with respect to its frequency and amplitude. Sorting out artifacts and random signals is the basis of the construction of data sets.

Data sets are the units of further analysis. I observed two ways of organizing data, so-called "channel sets" and "trial sets."

The occurrences measured by one electrode are recorded as the signals of one channel. For each trial, the neuronal events are recorded by several electrodes. The experimenters I observed used between one and sixteen electrodes simultaneously. A channel set contains the data of a set of artifact-free channels, independent of the number of trials selected. A trial set contains the data of a defined number of trials, independent of the number of channels selected. Sets are constructed so that it is always possible to go back to the original data, for example to construct subsets. For a subset one can choose, for example, only one trial and a small selection of electrodes. (Fieldnotes)

Well-organized datasets are malleable, so that they can be voluntarily reconstructed according to the necessities of the analysis. As such, they are the precondition for the next step. The data is transferred into an artificial multidimensional space in which the gestalt of the curves is analyzed, as well as their 
relationship to perceptual and behavioral events: Onset of stimulus, eye movements, performing a correct or incorrect response-all of these events may or may not be correlated with a particular pattern.

An advanced analysis of a curve's gestalt is the use of a "sliding window analysis." A curve originally represents a continuous signal. Through digitization, this is dissected into small pieces the length of, for example, $1 \mathrm{~ms}$. For this period the signal is treated as a static signal which no longer represents a time course. A typical analysis time window contains multiple data points, e.g. $800 \mathrm{~ms}$ in Fig. 1b. The analysis time window reflects the averaged time course of the signal across two different trial sets: trials with correct (grey curve) and trials with false responses (black curve). Alternatively, the analysis window may slide over the original curve's time course in steps smaller than the window itself, as depicted in "frequency space" in Fig. 1c and d. Here the time window is $200 \mathrm{~ms}$ long; the first $200 \mathrm{~ms}$ are analyzed. Then the time window slides $20 \mathrm{~ms}$. Now an overlapping data segment is analyzed, and so on for a period of $4.5 \mathrm{~s}$. Such an analysis can be

A

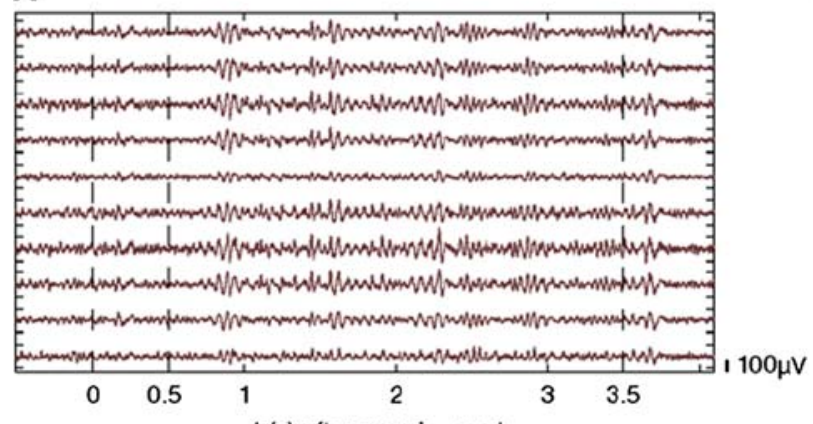

$\mathrm{t}$ (s) after sample onset

C $\mu \mathrm{V} / \mathrm{s}$

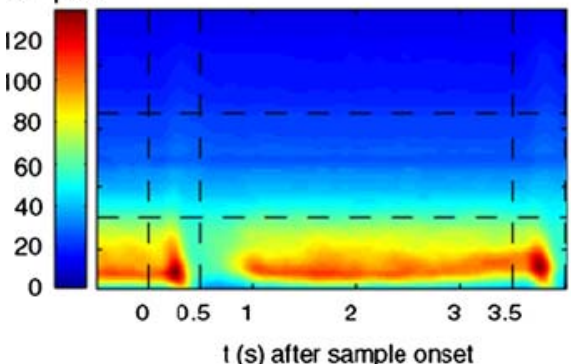

B

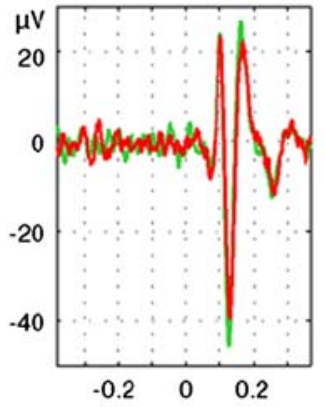

$t(s)$ after test onset
D

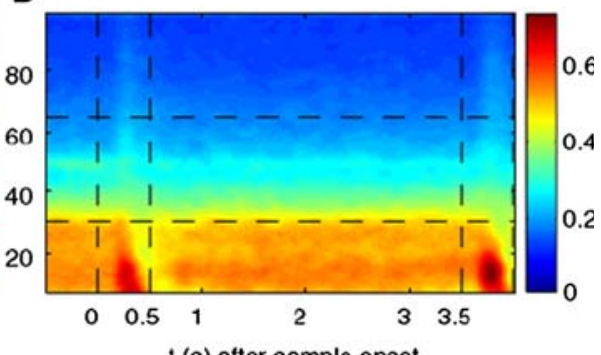

Fig. 1 Oscillations and stimulus responses in prefrontal cortex during a visual short-term memory task. a Ten simultaneous field potential recordings from microelectrodes in ventral prefrontal cortex, scale bar indicates $300 \mu \mathrm{V}$. Cursors denote stimulus on- and off-sets Other cursors represent the monkey's button press and the acoustic signal of the reward. b Visually evoked potentials for test stimulus onset. Latencies were determined by computing the distribution of averaged baseline values and picking the first of 5 or more bins that exceeded the 1st or 99th percentile. c, d Time-frequency plots of grand average power and phase-locking of all simultaneously recorded signals in one experiment. Different epochs are labeled with $\mathrm{S}$ (sample), D (delay), T (test) and R (response) (Paperdraft) 
performed with respect to frequency or to amplitude. The results and their relationship to perceptual and behavioral data are again represented visually in a two-dimensional space. The next pictures-including their descriptions-are taken from a draft version of a paper. ${ }^{18}$

Figure 1 shows the transformation process of data in a multidimensional space. Picture A presents raw data from a particular dataset. Picture B shows an "evoked potential signal;" it is "evoked" by an event in the environment of the brain. In this case it is the onset of the test stimulus. It is supposed to be impossible to identify such a signal by using only one trial and one channel. Instead, the data has to be pooled over many trials. Only then does the abrupt change become visible. Picture B also demonstrates another feature of data in the multidimensional space: the existence of a "baseline." The inherent problem is described by neurobiologists in this way: "There is no such thing as a baseline in a brain in an organism. A brain is never in the state of 'zero,' since it is always active and processing signals." (Fieldnotes) A baseline has to be constructed artificially in order to distinguish the brain before the onset of the stimulus and its perception (baseline brain activity), and the brain after onset/perception of stimulus.

During the training and the experimental session, researchers are dependent on monkeys as organisms developing and regulating their own relationship to their environment. In contrast to this, every operation in the artificial space is in the control of the scientist. Of course, there are technical problems. Sometimes an analysis requires more computer power than is available, and the analysis has to be split up, which in turn can cause further technical problems. Perhaps a computational cluster does not function or an analysis is not properly constructed. But there is no need to establish a trustful relationship with computers and analytical tools. They are not willful beings with their own interpretation of their environment. On the contrary, the elements of the artificial space can be constructed and reconstructed only by paying attention to mathematical logic and technical restrictions. There are no needs of living beings to be paid attention to.

Such an analysis is completed by adding psychological meaning to the representations produced in the multidimensional space. The measurement of eye movement is, for example, interpreted as an indication of being "attentive" or not. Pressing the button correctly when the sample stimulus appears is treated as an indication of a functioning working memory. Being attentive or memorizing is no longer an activity of the organism which it performs by using its brain. Instead it is a property of the brain itself.

With reference to the distinction between technical and epistemic objects and their relationship to the organism, it makes sense to describe the brain as it is malleably represented in the artificial multidimensional space as the epistemic object of neuroscience. It is no longer the brain as an organ of the organism that is of interest. It is the brain as a mechanical system which perceives the stimulus and responds to it. Not the organism but the brain is attentive and memorizes a stimulus.

\footnotetext{
18 This is a paper of a group of neuroscientists, which was discussed several times during my stay.
} 


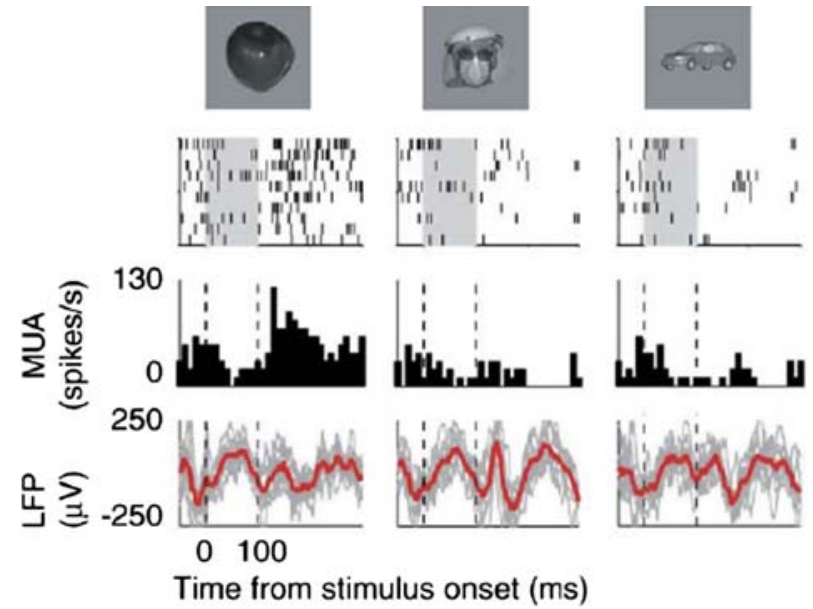

This figure illustrates the reactions of the epistemic object to stimuli, which are presented in the first line. The second and third lines show "spikes," and the fourth line a computed version of the trace of a smaller group of cells, a "Local Field Potential" (taken from Kreiman et al. 2006, p. 438).

What is the difference between the brain as the epistemic object and the brain as an organ of the organism? If one were to assume that the brain itself did not react to its environment, but the organism reacted using its brain as a means of steering its response, the analysis would be confronted with a new degree of freedom. The brain as an epistemic object of neuroscience is not easy to analyze, because "plasticity" is one of its crucial features. A brain adapts to an environment; it does not always react in exactly the same way. The brain as the organ of an organism would be even more difficult to analyze. It would be the plastic organ as used by the organism that formed the reaction. As such an organ, the brain could even be used differently in solving the same experimental task. ${ }^{19}$

I think that understanding the brain as the organ of self-regulation would result in two problems. The first of these is experimental in nature and easy to solve. There might not be only one pattern signifying a certain state-like being attentive or memorizing something or reacting-but instead a variety of patterns or a certain type of pattern. The second problem is of conceptual nature. In order to identify a pattern or a type of pattern it is necessary to construct an unambiguous relationship between, first, neuronal patterns and how these patterns are related to the functioning principles of the brain, and, second, the state the pattern is considered to signify (working memory, for example). If it is assumed that the brain is the

\footnotetext{
19 I leave it open how the relation between the organism as a whole and its organs can be conceptualized. But to understand the brain as an organ of self-regulation, it will be necessary to conceptualize it somehow. I would say that this is one of the crucial points to discuss if we are to develop a better mutual understanding between neuroscientists and social scientists. Usually social scientists do not treat actors as organisms. If they did, they could develop an understanding of the relevance of organs for social organisms. On the other hand, neuroscientists focus on the brain, and what they would need would be a theory of the organism.
} 
organ of self-regulation, the neuronal pattern can signify the state in two ways. First, the brain can be considered to be itself the (mechanical) system in question, in which case only its internal functional principles are relevant. Second, the brain is seen as a system which serves as an organ of the organism, therefore its functional principles are of relevance only with reference to its relation to the organism as a whole. My conclusion is: To make unambiguous sense of a detected pattern it seems to be necessary to make a decision. Experimentally detected patterns are only related to the brain as the system in question, and not to the brain as a means by which an organism steers itself. This seems to be an implicit precondition for identifying patterns of correct/incorrect answers. If the decision were not made, the way in which the actual documented traces of brain activity should be read would become an open question: as an indication of the brain as a system or of the brain as an organ in the service of the organism? ${ }^{20}$

The following figure is part of a PowerPoint presentation for a talk. It illustrates perfectly the steps from the behaving organism in front of the stimulus (upper left side) and the target area (upper right side) to the signal traces of the brain (lower left side) and, after the transformation of the signal into frequency space, the traces of the brain as an epistemic object (lower right side).

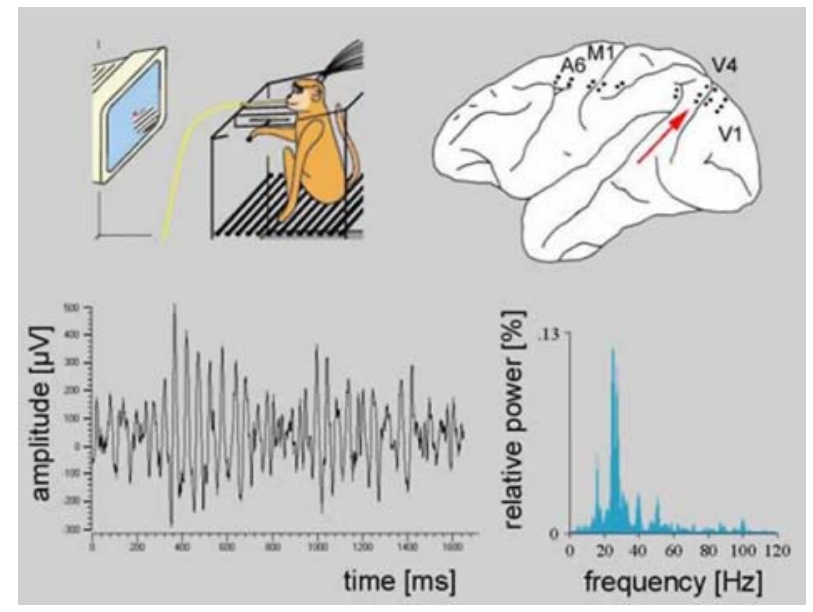

\section{Conclusion}

Neuronal expressivity is part of a complicated interaction process which provides the basis of the experiment. Although these aspects are seen as negligible once the experiment and, later, the analysis start, there is an inherent but implicit relationship between the structure of the interaction and the process of data analysis. At first

\footnotetext{
${ }^{20}$ The discussion on the brain in the vat, inspired by Hilary Putnam (Gere and Gere 2002), echoes philosophically the research perspective adopted by neurobiological research, which isolates the brain from the living organism and treats the brain as the system in question.
} 
glance, it seems that the aspect of interaction is simply ignored in its relevance as a precondition of neurobiological research. A closer look, however, reveals that analyzing neuronal data requires not only interacting with the macaque subject, but also that such interaction must have a certain structure.

For all practical purposes, the experimenter recognizes the monkey as an actor who treats the experiment as an element of his/her daily routine in a multiinteraction setting and not as an isolated episode. The scientist assumes that the subject (made thirsty through deprivation of liquids) will participate in the experiment only because s/he expects water or juice as a reward. Since the direct reaction to a series of images or stimuli results in the macaque subject receiving this reward, the scientist further assumes that the subject will respond directly many hundreds of times to the sequences of stimuli as a problem presented to him/her.

This description of the experimenter's interpretation of the monkey is based on an understanding of the monkey subject as an organism having expectations and acting accordingly. These are the features of centric positionality. The organism reacts directly to the stimulus, regardless of whether this occurs through cognitive learning or merely out of habit without any cognitive exertion. In assuming this, the experiment also systematically excludes a level of self-regulation that would make it impossible for us to classify the organism's behavior. Scientists assume that when an organism acts within the experimental order, it regulates its behavior according to the stimuli presented to it. In this way, its behavior can be understood as that of an organism presented with this specific stimulus.

If the organism, in contrast, were to relate to itself as part of the experimental order, it would regulate its behavior according to its own self-incorporation in the experiment. In other words, it would no longer react spontaneously as an organism, but instead as an organism that understands itself as a part of an experimental arrangement, within which expectations have been placed on it. If this were correct, an experimenter could no longer unambiguously attribute the subject's behavior to the organism; rather, s/he would always also have to understand this behavior as that of an organism relating to itself as a being that has expectations placed on it. Such an organism would no longer be characterized merely as a consciousness aware of its surroundings and acting accordingly; rather, it would also have to be understood as a self-consciousness, that is, as a self-conscious being in relation to another selfconscious being.

Understanding an organism solely as a conscious self renders that organism unambiguous. For if a subject reacts not only to the stimulus in the experiment, but always also relates to itself as part of the overall experimental situation, this gives rise to a specific kind of doubling. When the subject responds correctly, this can mean that it has understood what is going on and has answered accordingly. However, it can also mean that it has correctly responded because it wishes to present itself as a good or virtuous subject that does not want to disappoint the experimenter. And if the subject answers incorrectly, this may mean that it has not understood the task (stimulus-related), or that it is no longer motivated to take part in the experiment or has lost its concentration (stimulus-related, spontaneous reaction to the situation). However, it may also mean that it has understood the task correctly but has answered incorrectly because it wants to show annoyance with the 
experiment or wants to annoy the experimenter, that is, to disappoint the latter's expectations. Such behavior can no longer be understood in the sense of a spontaneous self-regulation but rather as the behavior of a social person, an excentric being, relating to itself as the performance of self-regulation.

The consequences of this are the following: If we assume that spontaneous behavior does not appear in pure form here, but rather that, in the sense of excentric positionality, a spontaneous consciousness is accompanied by a distance to itself, we are unable to unambiguously correlate the organism's behavior to its regulating function (which cannot be directly observed), or to correlate these to neuronal activity. It is then impossible for us to identify unambiguous neuronal patterns. While we could indeed identify neuronal patterns, and even if the above described problem (relationship between organ and organism) were to be solved, we would no longer be able to clearly determine what circumstances we should correlate these patterns to. It might be a correlate for a direct reaction to the stimulus or a direct reaction to the situation. However, it might also be a correlate for how the subject related to itself as a component of the situation in which it was presented with a task.

I use the phrase "the necessity of the organism's centric positionality in the experiment" to describe the circumstance in which the experimental interaction is constructed such that a subject reacts in an experimental situation but does not relate to this situation as such. A centric organism can develop expectations with regard to the course of the experiment. This can certainly include a subject reacting in a habituated manner to particular stimuli only in a particular situation, but outside of the habitual setting no longer reacting to the stimuli in this way. What is essential here is that the subject in no way relates to the expectations of the researcher implicit in the experimental arrangement. The centric positionality of the organism incorporates the organism into the experimental order and allows the researcher to control it. The centric organism is a rational actor who displays his/her order of preferences and acts accordingly in a calculable way. The intricate relationship between monkey subject and experimenter is always managed in terms of the monkey being a centric organism. It is essential for an experimenter that $\mathrm{s} / \mathrm{he}$ not be compelled to pose such questions as: Will the subject annoy me? Does the subject alter its behavior arbitrarily when dealing with other experimenters? Does the subject give incorrect responses at times, even though it is attentive and has understood what is going on?

This interpretation is supported by an internal critique of experiments on higher cognitive functions such as the match-to-sample experiment. According to this critique, subjects who have carried out a task many thousands of times become routinized, making them "overtrained." As a result, they no longer engage in any cognitive process when responding, but only in a kind of routinized or habitualized manner. In other words, the experiment in this situation does not examine a brain performing a cognitive function, but rather a brain engaging in routine activity. One neuroscientist involved in the experiment described this in approximately the following way: "If a monkey has repeated this so many times, it is doubtful that anything actually happens in the cortex." (Fieldnotes) 
This critique refers to the widely recognized idea of plasticity; that is, that the brain can adapt to new situations and therefore will not always react in the same way. The critique shares two basic assumptions with those who perform such experiments: Concerning the organism, it shares the assumption that the organism develops expectations and reacts accordingly - thereby treating the subject as a centric being. This would hold true for an organism which reacted habitually to a stimulus, and it would also hold true for an organism currently engaged in a cognitive process. Concerning the brain as an epistemic object, both interpretations share the assumption that the brain can be isolated from the organism-that the brain is the system in question.

The necessity of the organism's centric positionality exists also in experiments performed with human subjects, although incorporation of human subjects in parallel experimental arrangements occurs in a different manner. The actual experiment is framed by a communicative process in which the experimenter and the subject reach an agreement together about what is to take place in the experiment. $^{21}$ This includes mutual expectation-expectations and can thus be identified as the relationship of excentric beings. Only after this has been completed does the human subject actually participate in the experiment. Rather than using thirst and reward, the experimenter has to trust that the subject, in answering the "questions," responds solely to the stimuli of the experiment. Therewith, the experimenter assumes that for all practical purposes of analysis the experimental subject exists as a centric organism, which responds directly to stimuli. Paradoxically this holds true, although experimenters have to rely on a particular form of how subjects understand themselves as a part of the experimental situation as a whole: The experimenter trusts the subject as a subject, who always understands him/herself as a cooperative subject. Experimenter and human subject constitute communicatively, i.e. as excentric beings, the experimental framework. Once they move into that framework, the experimental subject has to be treated as a centric being for the same reasons as the monkey subject.

The necessity of centric positionality describes the necessary interaction presupposition for the identification of neuronal patterns that correspond to specific regulating processes or conditions of organisms. For only if we can unambiguously determine which regulatory phenomena we are seeking a neuronal correlate for can we attribute a particular neuronal signature to this. Nevertheless, formulating an unambiguous regulatory phenomenon is not sufficient. The brain itself must be conceived of in a particular way, since it must be transformed into an epistemic object beyond the organism.

Now we can describe more concretely what is meant by adopting a secondperson perspective in understanding biological phenomena. The starting point is sociation to social persons: At least two actors relate to each other such that they mutually expect the expectations of the other and behave accordingly. These organisms must not only have minds, but also be mind-reading organisms. By

\footnotetext{
${ }^{21}$ For a more detailed description of performing such agreement, see Roepstorff (2001, p. 761f). As I said, my analysis differs from his insofar as he restricts the second-person perspective to the communications among symbol-using humans.
} 
keeping the subject in the state of centric positionality, the research interaction is dissocialized. The researcher recognizes the subject as someone who expects something concerning the course of events in a certain situation. But the experimenter does not recognize the subject as expecting that the experimenter expects the (monkey) subject to do something. Since I have extended, following Plessner, the second-person perspective, it becomes obvious: The monkey subject is nonetheless understood and recognized as a conscious being (centric positionality), but not as a self-conscious social person (excentric positionality). So far, such differentiations have been overlooked in the analysis of laboratory life. Adopting a new conceptual framework has made the analysis sensitive enough to see them.

\section{References}

Birke, L., Arluke, A., \& Michael, M. (2006). The sacrifice: How scientific experiments transform animals and people. West Lafayette, IN: Purdue University Press.

Blum, D. (1994). The monkey wars. New York, Oxford: Oxford University Press.

Blumer, H. (1954/1986). What is wrong with social theory? In H. Blumer (Ed.), Symbolic interactionism. Perspective and method (pp. 140-152). Berkeley, Los Angeles, London: University of California Press.

Bohman, J. (2000). The importance of the second person: Interpretation, practical knowledge, and normative attitudes. In H. H. Kögler \& K. R. Stueber (Eds.), Empathy and agency. The problem of understanding in the human sciences (pp. 222-242). Boulder, CO: Westview Press.

Borck, C. (2002). Electricity as a medium of psychic life: Electrotechnological adventures into psychodiagnosis in Weimar Germany. Science in Context, 14, 565-590.

Burri, R. (2001). Doing images. Zur soziotechnischen Fabrikation visueller Erkenntnis in der Medizin. In B. Heintz \& J. Huber (Eds.), Mit dem Auge denken. Strategien der Sichtbarmachung in wissenschaftlichen und virtuellen Welten (pp. 277-303). Zürich: Edition Voldemeer.

Cavanagh, P. (1999). Top-down processing in vision. In R. A. Wilson \& F. C. Keil (Eds.), The MIT encyclopedia of the cognitive sciences (pp. 844-845). Cambridge, MA: MIT University Press.

Dror, O. E. (2002). Techniques of the brain and the paradox of emotions. Science in Context, 14, 643660.

Dumit, J. (2004). Picturing personhood: Brain scans and biomedical identity. Princeton, NJ: Princeton University Press.

Gere, C., \& Gere, C. (2002). The brain in a vat. Studies in History and Philosophy of Science Part C: Studies in History and Philosophy of Biological and Biomedical Sciences, 35, 219-436.

Glaser, B. G., \& Strauss, A. (1967). The discovery of grounded theory. Strategies for qualitative research. Chicago: Aldine.

Hagner, M. (2002). Cultivating the cortex in German neuroanatomy. Science in Context, 14, 541-563.

Hagner, M., \& Borck, C. (2002). Mindful practices: On the neurosciences in the twentieth century. Science in Context, 14, 507-510.

Haraway, D. (1990). Primate visions: Gender, race and nature in the world of modern science.. London: Routledge.

Harrington, A. (Ed.). (1992). So human a brain. Knowledge and values in the neurosciences. Boston, Basel, Berlin: Birkhäuser.

Hayward, R. (2002). The tortoise and the love-machine: Grey Walter and the politics of electroencephalography. Science in Context, 14, 615-641.

Ihde, D. (2006). Die Kunst kommt der Wissenschaft zuvor. Oder: Provozierte die Camera Obscura die Entwicklung der modernen Wissenschaft? In H. Schramm, L. Schwarte, \& J. Lazardzig (Eds.), Instrumente in Kunst und Wissenschaft (pp. 417-430). Berlin: Walter de Gruyter.

Kennedy, D. (2006). Editorial. Science, 313, 1541.

Kreiman, G., Hung, C. P., Kraskov, A., Quian Quiroga, R., Poggio, T., \& DiCarlo, J. J. (2006). Object selectivity of local field potentials and spikes in the macaque inferior temporal cortex. Neuron, 49, 433-445. 
Latour, B. (1994). On technical mediation-philosophy, sociology, genealogy. Common Knowledge, 3, $29-64$.

Latour, B. (2005). Reassembling the social. An introduction to actor-network-theory. Oxford: Oxford University Press.

Latour, B., \& Woolgar, S. (1979). Laboratory life. The social construction of scientific facts. London: Sage.

Lederer, S. (1992). Political animals: The shaping of biomedical research literature in the 20th century. Isis, 83, 61-79.

Lindemann, G. (2002). Die Grenzen des Sozialen. Zur sozio-technischen Konstruktion von Leben und Tod in der Intensivmedizin. München: Fink.

Lindemann, G. (2005). The analysis of the borders of the social world. A challenge for sociological theory. Journal for the Theory of Social Behaviour, 35, 69-98.

Lindemann, G. (2006). Soziologie - Anthropologie und die Analyse gesellschaftlicher Grenzregimes. In H.-P. Krüger \& G. Lindemann (Eds.), Philosophische Anthropologie im 21. Jahrhundert (pp. 4262). Berlin: Akademie Verlag.

Lindemann, G. (2007). Medicine as practice and culture: The analysis of border regimes and the necessity of a hermeneutics of physical bodies. In R. V. Burri \& J. Dumit (Eds.), Biomedicine as culture. Instrumental practices, technoscientific knowledge, and new modes of life (pp. 47-58). London, New York: Routledge.

Lindemann, G. (2008). Verstehen und Erklären bei Helmuth Plessner. In R. Greshoff, G. Kneer, \& W.-L. Schneider (Eds.), Verstehen und Erklären. Eine Einführung in methodische Zugänge zum Sozialen (pp. 117-142). München: Fink.

Loettgers, A. (2007). Getting abstract mathematical models in touch with nature. Science in Context, 20, $97-124$.

Luhmann, N. (1984). Soziale Systeme. [Social systems]. Frankfurt/Main: Suhrkamp.

Lynch, M. E. (1988). Sacrifice and the transformation of the animal body into a scientific object: Laboratory culture and ritual practice in the neurosciences. Social Studies of Science, 18, 265-289.

Michael, M., \& Birke, L. (1994). Accounting for animal experiments: Identity and disreputable "others". Science Technology Human Values, 19, 189-204.

Michalowski, R. J. (1996). Ethnography and anxiety: Field work and reflexivity in the vortex of U.S.Cuban relations. Qualitative Sociology, 19(5), 9-82.

Miller, E. K., Li, L., \& Desimone, R. (1993). Activity of neurons in anterior inferior temporal cortex during a short-term memory task. The Journal of Neuroscience, 73, 1460-1476.

Plessner, H. (1928/1975). Die Stufen des Organischen und der Mensch. Einleitung in die philosophische Anthropologie (3rd ed.). [The levels of the organic and man]. Berlin: de Gruyter.

Rammert, W. (2007). Technik - Handeln - Wissen. Zu einer pragmatistischen Technik- und Sozialtheorie. [Technic-action-knowledge]. Wiesbaden: VS.

Rees, D., \& Rose, S. (Eds.). (2005). The new brain sciences: Perils and prospects. Cambridge: Cambridge University Press.

Rheinberger, H.-J. (1992a). Experiment-Differenz-Schrift. Marburg: Basilisken-Presse.

Rheinberger, H.-J. (1992b). Experiment, difference, and writing: I. Tracing protein synthesis. Studies in the History and Philosophy of Science, 23, 305-331.

Roepstorff, A. (2001). Brains in scanners: An Umwelt of cognitive neurosicence. Semiotica, 134, 747765.

Roepstorff, A. (2002). Transforming subjects into objectivity. An ethnography of knowledge in a brain imaging laboratory. FOLK, Journal of the Danish Ethnographic Society, 44, 145-170.

Singer, W. (Ed.). (2002). Der Beobachter im Gehirn. Essays zur Hirnforschung. [The observer in the brain]. Frankfurt/Main: Suhrkamp.

Smith, R. (2002). Representations of mind: C. S. Sherrington and scientific opinion. Science in Context, $14,511-539$.

Solot, D., \& Arluke, A. (1997). Learning the scientist's role: Animal dissection in middle school. Journal of Contemporary Ethnography, 26, 28-54.

Wieder, D. L. (1987). Behavioristic operationalism and the life-world: Chimpanzees and chimpanzee researchers in face-to-face interactions. Sociological Inquiry, 50, 75-103.

Young, A. (2002). Our traumatic neurosis and its brain. Science in Context, 14, 661-683. 